\title{
Effect of Several Rootstocks on Fruit Quality of 'Sunburst' Sweet Cherry
}

\author{
S. Jiménez ${ }^{1}$, A. Garín ${ }^{1}$, E.S. Albás ${ }^{1}$, J.A. Betrán ${ }^{2}$, Y. Gogorcena ${ }^{1}$ \& M.A. Moreno ${ }^{1}$ \\ ${ }^{1}$ Department of Pomology. Estación Experimental de Aula Dei (EEAD-CSIC) \\ Consejo Superior de Investigaciones Científicas, Apdo. 202, 50.080 Zaragoza, Spain \\ ${ }^{2}$ Laboratorio Agroambiental (Diputación General de Aragón), Apdo. 727, 50.071 Zaragoza, \\ Spain
}

Keywords: Cherry, Prunus cerasus L., rootstock, fruit quality, sugar analysis

\begin{abstract}
The influence of CAB 6P, CAB 11E, Masto de Montañana (MM 9), MaxMa 14, MaxMa 97, GM 61/1 (Damil), Colt and Sainte Lucie GF 64 (SL 64) rootstocks on fruit quality of 'Sunburst' sweet cherry is studied. The experiment was performed in the Ebro Valley (Zaragoza, Spain), on a heavy and calcareous soil. To evaluate the effect of rootstocks, parameters such as fruit size, fresh weight, colour, firmness and some chemical fruit properties (acidity, $\mathrm{pH}$ and soluble solid content) have been determined. In addition, the most important sugars present in fruit juice (glucose, fructose and sorbitol), were analysed by High Performance Liquid Chromatography (HPLC). Significant differences in sugar concentrations, colour parameters, fruit weight and firmness were found among rootstocks. The highest fruit weight and diameter were induced by $P$. cerasus and 'Colt' rootstocks, especially for the high-yielding years. Preliminary results indicate that rootstocks with high total soluble solids in fruits also showed high values for fruit firmness.
\end{abstract}

\section{INTRODUCTION}

Nowadays, an important requirement for a breeder is not only the productivity, but the quality of fruit obtained from the rootstock-cultivar combination and its adaptation to different soil types.

Influence of rootstocks on fruit size and yield is known (Facteau et al., 1996; Moreno et al., 2001). According to Westwood (1993), the more common effects of rootstocks on fruit quality are differences of firmness, levels of organic acids and sugar content. The three major components of fruit organoleptic quality are flavour, sweetness and acidity, which are highly correlated to several chemical and physical fruit properties (Crisosto et al., 2002).

The present study was carried out over three years with 'Sunburst' sweet cherry growing under calcareous soil conditions. The characteristics of yield, vigour and foliar prognosis were studied in previous work up until 1998 (Moreno et al., 2001). In the present work, the objective was to determine the relative influence of rootstock on fruit quality parameters and some chemical fruit properties. Moreover, we evaluated the sugar composition of fruits.

\section{MATERIAL AND METHODS}

\section{Plant Material}

The rootstocks under study included three sour cherry (Prunus cerasus) selections: CAB 6P, CAB 11E, and Masto de Montañana 9 (MM 9); two selections considered to be of $P$. mahaleb $\times P$. avium parentage: MaxMa 14 and MaxMa 97; one selection of $P$. dawyckensis: Grand Manil GM 61/1 (Damil); a P. mahaleb: Sainte Lucie GF 64 (SL 64) and a $P$. avium $\times P$. pseudocerasus: Colt. They were grafted in situ with 'Sunburst' sweet cherry during the summer of 1989.

\section{Trial Characteristics}

The trial was carried out at the Estación Experimental de Aula Dei (Zaragoza, Spain) on calcareous soil, with $35 \%$ total calcium carbonate, $8 \%$ active lime, $\mathrm{pH}$ in water 8.0 , and a clay-loam texture. The experiment was designed as described in Moreno et al. (2001). 


\section{Yield and Fruit Characteristics}

Besides the yield (Kg/tree), mean fruit weight (g), vigour [through the calculation of the trunk cross-sectional area (TCSA), from the measurement of the cultivar trunk girth circumference, $20 \mathrm{~cm}$ above the graft], and yield efficiency (Kg cumulative yield $/ \mathrm{cm}^{2}$ of TCSA), fruit quality characteristics were analysed. For 1999, 2000 and 2001, yield, mean fruit weight and size were recorded.

In 2001, yield was much less abundant. During this harvest, 50 fruits of each tree were randomly selected, to estimate fruit quality. Several physical-chemical parameters were considered, such as colour, acidity, $\mathrm{pH}$ and firmness. The solid soluble concentration (SS), $\mathrm{pH}$ and the acidity were also considered as organoleptic properties.

Concentration of soluble solids (SS) content $\left({ }^{\circ}\right.$ Brix) from fruit juice from each sample was measured using an Atago PR-101 digital refractometer. Titratable acidity (TA) was determined on a sample of juice from 50 fruits. The juice samples were diluted with distilled water (1:10), and microtitrated with $0.1 \mathrm{~mol} \cdot \mathrm{l}^{-1} \mathrm{NaOH}$. The fruit colour was measured with a Minolta colorimeter (Minolta, CR-200, Japan). For each sample, values from parameters L*, $\mathrm{a}^{*}$ and $\mathrm{b}^{*}$ were assigned. Firmness was estimated by a durometer (Shore A, Durofel), a nondestructive method, whose value (from 0 to 1 ) is relative (Kappel et al., 2000).

\section{Sugar Analysis}

The juice was extracted. Soluble sugars of $1 \mathrm{ml}$ juice were fixed for $15 \mathrm{~min}$ with $1 \mathrm{ml}$ ethanol/water $(80: 20, \mathrm{v}: \mathrm{v})$ at $80^{\circ} \mathrm{C}$. The mixture was centrifuged (3600g for $\left.15 \mathrm{~min}\right)$. The supernatant was used for analysis of soluble sugar.

Soluble sugars were purified using ion exchange resins (Bio-Rad AG 1-X4 Resin 200400 chloride form, Bio-Rad AG 50W-X8 Resin 200-400 mesh hydrogen form) (Moing et al., 1998). The samples were concentrated to $1 \mathrm{ml}$ and analysed by high-performance liquid chromatography (HPLC) using a Ca-column (Aminex HPX-87C $300 \mathrm{~mm} \times 7.8 \mathrm{~mm}$ column Bio-Rad) flushed with $0.6 \mathrm{ml} \cdot \mathrm{min}^{-1}$ deionised water at $85^{\circ} \mathrm{C}$ with a refractive index detector (Waters 2410). Twenty microliters of sample was injected.

Concentrations of sucrose, fructose, glucose and sorbitol were analysed for each tree/rootstock. Manitol was included in the sum of sugars as an internal standard.

Sugar quantification was carried out with Millennium 3.2 software from Waters (Milford, Mass). HPLC peaks were identified using commercial standards. Peak areas were calculated, and calibration was carried out using external standards of known quantities of sugars from Panreac Quimica S.A. Standard solutions were prepared in water.

\section{Analysis of Data}

Data were evaluated by analysis of variance with SSPS 10.0 (Norusis, 1999). When the F test was significant, means were separated by Duncan's test $(P \leq 0.05)$.

\section{RESULTS AND DISCUSSION}

\section{Cumulative Yield and Yield Efficiency}

As previously reported, cumulative yield and yield efficiency of the plantation (Table 1) were generally larger on $P$. cerasus rootstocks (MM 9, CAB 6P and CAB 11E), intermediate on Colt, SL 64, MaxMa 14 and MaxMa 97 rootstocks, and much lower on Damil (Moreno et al., 2001).

\section{Mean Fruit Weight}

In the three last years, the fruit weight mean was analysed (Table 1). In 1999, differences between rootstocks were not statistically significant. In 2000, mean fruit weight was greater on MM 9, CAB 6P and CAB 11E. In 2001, SL 64 and Damil induced the lowest fruit weight. The values of fruit weight were higher the last year because of the lowest yield.

Regarding the mean, $\mathrm{CAB} 11 \mathrm{E}$ showed the highest mean fruit weight, followed by CAB 6P, MM 9 and Colt. On the other hand, the lowest values were recorded on SL 64, 
although this did not differ significantly from MaxMa 14, MaxMa 97, Damil and Colt.

\section{Size}

Table 2 shows all the parameters of fruit size that have been considered in the study. For the greater fruit width, MaxMa 14, CAB 11E, CAB 6P and Colt rootstocks showed the highest values. CAB $11 \mathrm{E}$ and Colt promoted lesser width in the other direction, followed by CAB 6P and MaxMa 14. The fruit height was higher on Colt, although differences were not significant when compared with CAB 11E and MaxMa 14. The lowest fruit height was shown on Damil and SL 64. On the other hand, fruit height and tree vigour were positively related $(r=0.46 ; p \leq 0.01)$ in 2001. Damil presented the lowest value of height/width, and Colt showed the highest value without differing significantly from MaxMa 97 and SL 64.

The high fruit weight observed in 2001 is probably due to the low yields for this year. This has been demonstrated previously by Proebsting (1990). Nevertheless, the influence of rootstocks on fruit size is also demonstrated in this study. Thus, the tendency of $P$. cerasus and Colt to induce greater fruit size was observed, confirming previous results, based on the first productive years of the orchard (Moreno et al., 2001).

Regarding the height/width relation, Damil rootstock showed the lowest value, inducing fruit-flattening, with significant differences with respect to the other rootstocks. On the other hand, Colt showed lengthened fruits. These differences in the fruit form are interesting, since a flattened cherry seems more tempting than a lengthened one.

\section{Skin Colour}

MaxMa 14 showed the highest values for the three parameters $\mathrm{L}^{*}, \mathrm{a}^{*}$ and especially $b^{*}$ (Table 2). On the other hand, CAB 11E induced a clearer red skin colour. Probably, cherries of MaxMa 14 rootstock will be more attractive for the consumer, showing a dark red skin colour (Crisosto et al., 2002)

\section{Soluble Solids Concentration}

In 2001, the highest concentration of SS ( ${ }^{\circ}$ Brix) was observed on Damil, MaxMa 14 and Colt rootstocks (Table 3), the latter did not differ from CAB 6P, CAB 11E and MaxMa 97 rootstocks. In addition, Damil rootstock showed greater SS/TA. However, SL 64 showed the lowest SS concentration. In a previous report (Moreno et al., 2001), Colt also induced a greater concentration of SS than the other rootstocks.

In 2001, all fruits were much sweeter than in previous years, gaining taste quality. The lowest production observed in this year, especially on some rootstocks, seems to allow higher SS quantity, due to lesser competition between fruits. A negative relationship between yield/tree and SS in fruits ( $r=-0.79 ; p \leq 0.01)$ was shown in 2001 (Fig. 1).

\section{Titratable Acidity and pH}

In 2001, TA and pH were not significantly affected by rootstocks (Table 3). However, in a previous report, the $P$. cerasus selections induced the greatest TA in fruit (Moreno et al., 2001). This could be due to the greater yield of these rootstocks.

\section{Firmness}

The firmness was greater on Damil, followed by Colt, CAB 6P and MaxMa 14 (Table 3). It was lowest on CAB 11E, followed by MM 9. A positive relationship has been observed between firmness and SS of fruit $(r=0.50 ; p \leq 0.01)$.

\section{Sugar Analysis}

In fruit juice, the major soluble sugars were glucose, fructose and sorbitol. The glucose and fructose concentration were about three times and twice the sorbitol concentration respectively. On the other hand, sorbitol concentration was greater compared to other stone fruit species. However, sucrose concentration was very low, as with other minor soluble sugars (data not presented). The values of sugars agree with data obtained in SS.

Rootstock differences in terms of glucose, fructose and sorbitol concentration in fruits 
have been observed (Table 4). Concentration of glucose and fructose were greater on Damil, although differences were not significantly greater than Colt and MaxMa 14. While concentration of glucose and fructose were lower on SL 64, these did not differ significantly in $\mathrm{CAB}$ 6P, CAB 11E, MM 9 and MaxMa 97. Concentration of sorbitol was significantly higher on Damil, probably due to its low yield, while no significant differences were found between all the other rootstocks.

\section{CONCLUSION}

In general, the P. cerasus selections (CAB 6P, CAB 11E and MM 9) induced greater fruit calibre and fruit weight. In addition, they showed higher yields probably because of a better adaptation to heavy and calcareous soil. Colt rootstock also showed greater calibre and fruit weight and an intermediate level of yield.

The semi-dwarfing habit of MaxMa 14 and high fruit quality may be interesting. Nevertheless, the fruit size of MaxMa 14 is reduced in high-yielding years. Colt appeared to induce higher SS values as previously reported, in spite of the unfavourable growing conditions for this rootstock (chlorosis problems).

Good cherry quality attributes of Damil fruits could be due to a higher maturity index (SS/TA) and limited yield, hence the lower competition between fruits.

\section{ACKNOWLEDGEMENT}

This work was supported by Comisión Interministerial de Ciencia y Tecnología projects (AGL 2001-2302 and AGL 2002-04219).We thank Dr. J. Pinochet for critical reading of the manuscript, as well as J. Aparicio and J. Pérez for the management of plant material in the orchard.

\section{Literature Cited}

Crisosto, C.H., Crisosto, G.M. and Ritenour, M.A. 2002. Testing the reliability of skin color as an indicator of quality for early season 'Brooks' (Prunus avium L.) cherry. Postharvest Biology and technology, 24: 147-154.

Facteau, T.J., Chestnut, N.E. and Rowe, K.E. 1996. Tree, fruit size and yield of 'Bing' sweet cherry as influenced by rootstock, replant area, and training system. Scientia Horticulturae, 67: 13-26.

Kappel, F., David, D.L., MacDonald, R.A. and Schmid, H. 2000. 'Skeena' sweet cherry. Hortscience, 35(2): 306-307.

Moing, A., Rolin, D., Gaudillère, M., Gaudillère, J.P. and Monet, R. 1998. Compositional changes during the fruit development of two peach cultivars differing in juice acidity. $\mathrm{J}$. Amer. Soc. Hort. Sci. 123(5): 770-775.

Norusis, M.S.J. 1999. Statistical package for the social sciences/PC+ for the IBM PC/XT/AT. SPSS Inc., Chicago IL.

Moreno, M.A., Adrada, R., Aparicio, J. and Betrán, J.A. 2001. Performance of 'Sunburst' sweet cherry grafted on different rootstocks. J. Hort. Sci. \& Biotech., 76(2): 167-173.

Proebsting, E.L. 1990. The interaction between fruit size and yield in sweet cherry. Fruit Varieties Journal, 44(3): 169-172.

Westwood, M.N. 1993. Temperate-Zone Pomology. Timber Press. $3^{\text {rd }}$ Edition. Portland, Oregon. 523 pp. 


\section{$\underline{\text { Tables }}$}

Table 1. Rootstock effects on trunk cross-sectional area (TCSA) and yield of 'Sunburst' sweet cherry after 11 years in the orchard.

\begin{tabular}{|c|c|c|c|c|c|c|c|}
\hline \multirow[b]{2}{*}{ Rootstock } & \multirow[t]{2}{*}{$\begin{array}{l}\text { TCSA } \\
\left(\mathrm{cm}^{2}\right)\end{array}$} & \multirow{2}{*}{$\begin{array}{c}\text { Cumulative } \\
\text { yield } \\
\text { (Kg/tree) }\end{array}$} & \multirow{2}{*}{$\begin{array}{c}\text { Yield } \\
\text { efficiency } \\
\left(\mathrm{Kg} / \mathrm{cm}^{2}\right)\end{array}$} & \multicolumn{4}{|c|}{$\begin{array}{l}\text { Mean fruit } \\
\text { weight (g) }\end{array}$} \\
\hline & & & & 1999 & 2000 & 2001 & Mean \\
\hline CAB 6P & $587 \mathrm{~b}$ & 317 bcd & $0.56 \mathrm{~cd}$ & $9.2 \mathrm{a}$ & $8.2 \mathrm{c}$ & $13.0 \mathrm{~b}$ & $10.1 \mathrm{bc}$ \\
\hline CAB 11E & $562 \mathrm{~b}$ & 297 bcd & $0.53 \mathrm{bcd}$ & $10.6 \mathrm{a}$ & $8.2 \mathrm{c}$ & $13.0 \mathrm{~b}$ & $10.6 \mathrm{c}$ \\
\hline MM 9 & $586 \mathrm{~b}$ & $345 \mathrm{~cd}$ & $0.60 \mathrm{~d}$ & $9.6 \mathrm{a}$ & $7.9 \mathrm{c}$ & $12.7 \mathrm{~b}$ & 9.9 bc \\
\hline MaxMa 14 & $534 \mathrm{~b}$ & 236 bc & $0.44 \mathrm{~b}$ & $8.6 \mathrm{a}$ & $5.4 \mathrm{ab}$ & $13.2 \mathrm{~b}$ & $9.1 \mathrm{ab}$ \\
\hline MaxMa 97 & $495 \mathrm{~b}$ & 232 bc & $0.45 \mathrm{bc}$ & 8.9 a & $5.6 \mathrm{ab}$ & $12.7 \mathrm{~b}$ & $9.1 \mathrm{ab}$ \\
\hline Damil & $332 \mathrm{a}$ & $28 \mathrm{a}$ & $0.10 \mathrm{a}$ & $10.2 \mathrm{a}$ & $4.9 \mathrm{a}$ & $11.7 \mathrm{a}$ & $9.2 \mathrm{ab}$ \\
\hline Colt & $625 \mathrm{~b}$ & 252 bc & $0.42 \mathrm{~b}$ & $9.5 \mathrm{a}$ & $6.5 \mathrm{~b}$ & $13.3 \mathrm{~b}$ & $9.8 \mathrm{abc}$ \\
\hline SL 64 & 562 b & $213 b$ & $0.47 \mathrm{bc}$ & $8.5 \mathrm{a}$ & $6.3 \mathrm{~b}$ & $11.6 \mathrm{a}$ & $8.8 \mathrm{a}$ \\
\hline
\end{tabular}

For each column, means followed by the same letter are not significantly different according to the Duncan test $(\mathrm{p} \leq 0.05)$.

Table 2. Rootstock effects on fruit size and skin colour of 'Sunburst' sweet cherry.

\begin{tabular}{|c|c|c|c|c|c|c|c|}
\hline \multirow[b]{2}{*}{ Rootstock } & \multicolumn{4}{|c|}{ Size (mm) } & \multicolumn{3}{|c|}{ Colour } \\
\hline & Width 1 & Width 2 & Height & Height/Width & $\mathrm{L}^{\prime}$ & $\mathrm{a}^{*}$ & $\mathrm{~b}^{*}$ \\
\hline CAB 6P & $29.6 \mathrm{~cd}$ & $24.8 \mathrm{c}$ & 25.7 bc & 0.944 bc & $33.5 \mathrm{c}$ & $27.6 \mathrm{c}$ & $10.2 \mathrm{~b}$ \\
\hline CAB 11E & $30.0 \mathrm{~d}$ & $25.4 \mathrm{~d}$ & $26.0 \mathrm{~cd}$ & $0.939 \mathrm{~b}$ & 31.5 a & $21.8 \mathrm{a}$ & $8.7 \mathrm{a}$ \\
\hline MM 9 & $29.1 \mathrm{~b}$ & 24.6 bc & $25.4 \mathrm{~b}$ & 0.944 bc & $32.3 \mathrm{~b}$ & $24.5 \mathrm{~b}$ & $10.0 \mathrm{~b}$ \\
\hline MaxMa 14 & $30.1 \mathrm{~d}$ & 24.9 c & $25.9 \mathrm{~cd}$ & $0.946 \mathrm{bc}$ & 33.7 c & $27.7 \mathrm{c}$ & $11.7 \mathrm{C}$ \\
\hline МaxМa 97 & $29.2 \mathrm{bc}$ & $24.2 \mathrm{a}$ & $25.5 \mathrm{~b}$ & $0.951 \mathrm{~cd}$ & $32.8 \mathrm{bc}$ & $27.0 \mathrm{c}$ & $9.9 \mathrm{~b}$ \\
\hline Damil & $28.8 \mathrm{~b}$ & $24.3 \mathrm{ab}$ & $24.9 \mathrm{a}$ & $0.932 \mathrm{a}$ & $32.8 \mathrm{bc}$ & $26.2 \mathrm{bc}$ & $9.6 \mathrm{~b}$ \\
\hline Colt & $29.6 \mathrm{~cd}$ & $25.2 \mathrm{~d}$ & $26.1 \mathrm{~d}$ & $0.954 \mathrm{~d}$ & $33.1 \mathrm{bc}$ & $26.3 \mathrm{bc}$ & $10.8 \mathrm{~b}$ \\
\hline SL 64 & $28.3 \mathrm{a}$ & $24.4 a b$ & $24.9 \mathrm{a}$ & $0.949 \mathrm{~cd}$ & $32.6 \mathrm{~b}$ & $26.2 \mathrm{bc}$ & $9.8 \mathrm{~b}$ \\
\hline
\end{tabular}

For each column, means followed by the same letter are not significantly different according to the Duncan test $(\mathrm{p} \leq 0.05)$.

Table 3. Rootstock effects on firmness, pH, SS, acidity and SS/acidity of 'Sunburst' sweet cherry.

\begin{tabular}{lccccc}
\hline Rootstock & Firmness & $\mathrm{pH}$ & SS ( ${ }^{\circ}$ Brix) & $\begin{array}{c}\text { TA (g malic } \\
\text { acid/l juice) }\end{array}$ & SSC/TA \\
\hline CAB 6P & $0.51 \mathrm{e}$ & $3.8 \mathrm{a}$ & $19.7 \mathrm{c}$ & $9.5 \mathrm{a}$ & $2.05 \mathrm{a}$ \\
CAB 11E & $0.34 \mathrm{a}$ & $3.7 \mathrm{a}$ & $19.7 \mathrm{c}$ & $9.0 \mathrm{a}$ & $2.20 \mathrm{a}$ \\
MM 9 & $0.41 \mathrm{~b}$ & $3.6 \mathrm{a}$ & $19.1 \mathrm{~b}$ & $9.0 \mathrm{a}$ & $2.16 \mathrm{a}$ \\
MaxMa 14 & $0.48 \mathrm{~d}$ & $3.7 \mathrm{a}$ & $20.5 \mathrm{~d}$ & $9.1 \mathrm{a}$ & $2.17 \mathrm{a}$ \\
MaxMa 97 & $0.44 \mathrm{c}$ & $3.4 \mathrm{a}$ & $19.9 \mathrm{c}$ & $8.7 \mathrm{a}$ & $2.32 \mathrm{a}$ \\
Damil & $0.55 \mathrm{f}$ & $3.7 \mathrm{a}$ & $22.4 \mathrm{e}$ & $8.5 \mathrm{a}$ & $2.70 \mathrm{~b}$ \\
Colt & $0.51 \mathrm{e}$ & $3.7 \mathrm{a}$ & $20.3 \mathrm{~cd}$ & $9.2 \mathrm{a}$ & $2.23 \mathrm{a}$ \\
SL 64 & $0.44 \mathrm{c}$ & $3.6 \mathrm{a}$ & $18.3 \mathrm{a}$ & $8.4 \mathrm{a}$ & $2.18 \mathrm{a}$ \\
\hline
\end{tabular}

For each column, means followed by the same letter are not significantly different according to the Duncan test $(\mathrm{p} \leq 0.05)$. 
Table 4. Rootstock effects on sugar content of 'Sunburst' sweet cherry.

\begin{tabular}{lccc}
\hline & \multicolumn{3}{c}{ Sugar concentration (mg/ml juice) } \\
\cline { 2 - 4 } Rootstock & Glucose & Fructose & Sorbitol \\
\hline CAB 6P & $80.0 \mathrm{ab}$ & $64.8 \mathrm{ab}$ & $27.4 \mathrm{a}$ \\
CAB 11E & $78.8 \mathrm{ab}$ & $64.2 \mathrm{ab}$ & $26.5 \mathrm{a}$ \\
MM 9 & $78.3 \mathrm{ab}$ & $64.1 \mathrm{ab}$ & $26.2 \mathrm{a}$ \\
MaxMa 14 & $82.3 \mathrm{abc}$ & $67.3 \mathrm{abc}$ & $29.9 \mathrm{a}$ \\
MaxMa 97 & $80.2 \mathrm{ab}$ & $65.5 \mathrm{ab}$ & $28.5 \mathrm{a}$ \\
Damil & $88.0 \mathrm{c}$ & $73.0 \mathrm{c}$ & $35.6 \mathrm{~b}$ \\
Colt & $84.3 \mathrm{bc}$ & $69.7 \mathrm{bc}$ & $30.3 \mathrm{a}$ \\
SL 64 & $75.9 \mathrm{a}$ & $61.0 \mathrm{a}$ & $26.1 \mathrm{a}$ \\
\hline
\end{tabular}

For each column, means followed by the same letter are not significantly different according to the Duncan test $(\mathrm{p} \leq 0.05)$.

\section{$\underline{\text { Figures }}$}

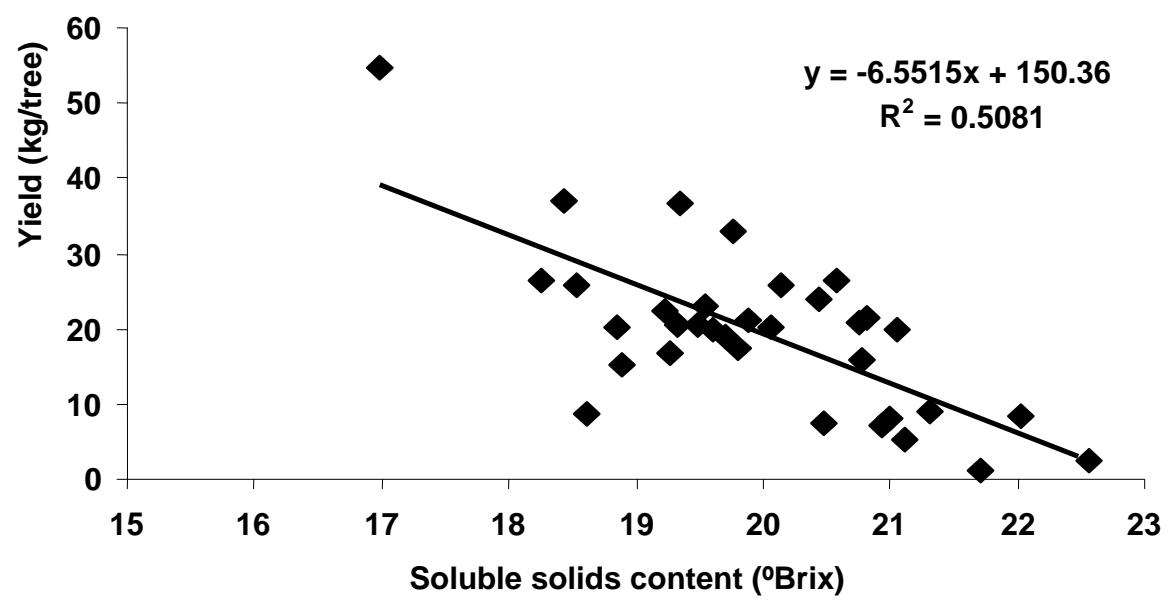

Fig. 1. Yield and soluble solids content of fruits relationship in 2001. 